\title{
O JORNALISMO NA ECONOMIA DE MERCADO: ESTUDO DA REVISTA VEJA
}

\section{Journalism in the Marketing Economy: A Study of Veja Magazine}

\section{Periodismo en la Economía de Mercado: un estudio de la revista Veja}

\author{
Maria Inez Mateus Dota ${ }^{1}$ \\ Denise Fernandes Britto ${ }^{2}$
}

\section{Resumo}

As relações econômicas, somadas aos aspectos sociais, culturais e históricos, influenciam no processo jornalístico, desde o interesse por uma pauta até a edição final da notícia. Tendo em vista essa rotina, buscamos destacar como a economia de mercado está presente na materialidade discursiva da revista Veja. Para tanto, analisamos os aspectos verbal e não-verbal de uma reportagem de Saúde publicada na revista, verificando o consumo como uma das finalidades jornalísticas da atualidade.

Palavras-chave: jornalismo, discurso, economia de mercado, consumo.

\begin{abstract}
Economic relations, added to the social, cultural and historical aspects, influence the journalistic process, from the interest in an agenda to the final edition of the news. Having this routine in mind, we seek to highlight how the market economy is present in the discursive materiality of Veja magazine. Therefore, we analyze the verbal and nonverbal aspects of an article about Health published in the magazine, checking consumption as one of the purposes of journalism nowadays.
\end{abstract}

Keywords: journalism, discourse, market economy, consumption.

\section{Resumen}

\footnotetext{
${ }^{1}$ Doutora em Letras pela UNESP-Araraquara e professora do Programa de Pós-Graduação em Comunicação da UNESP, em Bauru, SP. End. Rua Benjamin Constant, 1-48, Bauru, SP. Tel. (14) 32346673.

${ }^{2}$ Jornalista e Mestre em Comunicação pela UNESP-Bauru. Atualmente é professora nos cursos de Jornalismo e Publicidade e Propaganda do Imesb (Instituto Municipal de Ensino Superior de Bebedouro). End. Rua dos Trabalhadores, 228, Jaboticabal, SP. Tel. (16) 32022307
} 
Las relaciones económicas, sumadas a la influencia social, cultural e histórica en el proceso periodístico, desde el interés en un facto hasta la edición final de la noticia. En vista de esta rutina, tratamos de poner de relieve como la economía de mercado está presente en la materialidad discursiva de la revista Veja. Por lo tanto, analizamos los aspectos verbal y no verbal de un artículo publicado en la revista de salud, verificando el consumo como uno de los propósitos de periodismo de hoy.

Palabras-clave: periodismo, discurso, economía de mercado, consumo.

\section{INTRODUÇÃO}

Nos estudos referentes à comunicação midiática, é crescente a atenção que pesquisadores têm dado a áreas relativas à saúde. Uma das razões é o próprio olhar da mídia que se volta a essas questões, ora divulgando novos fármacos, ora relatando o desenvolvimento e resultado das pesquisas médicas.

Os avanços do Brasil na área, em relação a tempos passados, acaba pautando, de certa forma, a mídia, que, diante de um assunto crescente, não pode deixar de cobrir essas matérias.

Avançando nessas observações, percebemos que a área da saúde pode se apresentar de modo conexo com outras temáticas, sendo as mais comuns a beleza, o comportamento e a estética. Essa convergência, todavia, suscita algumas questões como: quais são os limites entre saúde e beleza? Os dois temas caminham sempre juntos? Qual desses aspectos é mais valorizado pela mídia? Até que ponto o interesse das indústrias (em essencial a de farmacologia e a cosmética) impõe suas visões aos conteúdos jornalísticos? O leitor é visto como um cidadão que tem direito à saúde ou é encarado como um consumidor de uma indústria que se renova com muita rapidez? Todas essas dúvidas se enquadram na discussão de como as relações econômicas afetam a mídia, nossa maior problemática. Vemos, assim, como essas condicionantes do mercado estão manifestadas no discurso jornalístico que aborda o binômio editorial saúde-beleza.

O objetivo central deste trabalho é identificar, nas marcas textuais, a materialidade discursiva referente à economia vigente em nossa sociedade. A problemática do estudo consiste no fato de que as bases estruturais, aliadas às bases históricas e culturais, têm influenciado o jornalismo de modo a desvirtuá-lo de seus reais propósitos de informar a sociedade de modo responsável. Assim, nosso olhar se 
volta a esse fenômeno, levando em consideração os fatores econômicos, ideológicos, culturais, sociais e históricos.

Para isso, desenvolvemos um trabalho cuja versão completa estudou sete reportagens de saúde e beleza da revista Veja. Como nossa intenção era identificar as marcas econômicas manifestadas no discurso, selecionamos os temas de beleza e saúde. Trata-se de assuntos conexos, correlacionados e que viabilizariam este estudo no aprofundamento de uma área econômica profícua: das indústrias de cosméticos e de remédios.

A princípio, adquirimos os exemplares do segundo semestre de 2004. Dessas revistas, selecionamos um mês em que foram publicadas mais reportagens de saúde e beleza. Assim, estudamos sete reportagens dos cinco exemplares do mês de outubro. Para este artigo, especificamente, selecionamos uma das sete matérias, intitulada $E$ possível, sim, ser feliz, enquadrada pela revista como uma reportagem de saúde, mas que apresenta características do texto de beleza.

Com isso, esperamos, de maneira dialética, enxergar a integração de partes que envolvem o jornalismo de saúde e beleza, suas condições de produção e o contexto sócio-econômico mais amplo.

\section{EMBASAMENTO TEÓRICO-METODOLÓGICO}

Levamos em conta que cada reportagem faz, por meio do discurso, uma representação da realidade. A enunciação agrega, então, um caráter metonímico em que o enunciador realiza inúmeras escolhas e deixa para trás, ao mesmo tempo, milhares de outras opções discursivas. Ele cria, assim, uma representação, costurada com as palavras e os elementos de imagem.

Seguindo a linha analítica de que cada reportagem é uma representação, destacaremos os elementos que aparecem em todas as matérias e que constituem essas reportagens, construindo, discursivamente, o cenário e os personagens que nele atuam. Nosso foco será sempre as materialidades discursivas que permitirão verificar na superfície textual a estrutura econômica sob o discurso. Para tanto, seguiremos categorias salientadas pelos estudos de Maingueneau (1997/2004), na Análise de Discurso (AD). 
Já para a leitura sistemática das imagens estampadas nas reportagens, levaremos em conta os estudos de Roland Barthes (1990) e Joly (2005) - que segue a linha de Barthes. Esses autores não se chocam com a AD e fornecem, ao mesmo tempo, uma contribuição significativa para a decodificação e aprofundamento dos sentidos do imagético que, por parecer algo natural, universal e de fácil fruição, esconde seus níveis mais profundos, suas intenções, sua mensagem implícita.

\section{CATEGORIAS DE ANÁLISE}

Para empreendermos nossa análise textual, destacamos as categorias elencadas por Maingueneau (2004) para analisar textos em comunicação, mais especificamente, os de caráter publicitário. Notemos que, mesmo nosso corpus sendo constituído por reportagens jornalísticas, as categorias do texto publicitário são encontradas no discurso jornalístico de Veja.

Após a explicitação dessas categorias, desenvolvemos a análise da reportagem $E$ possivel, sim, ser feliz.

\subsection{Contexto}

Para Dahlet, é preciso notar que o discurso, que constrói a significação de uma representação, “o faz, por um lado, contestando as fronteiras de um objeto do mundo [...] e, por outro lado, deixando, 'assim', instruções para a interpretação do leitor”. (Dahlet 1994: 109).

A interpretação dos enunciados varia conforme um repertório do destinatário. Koch e Travaglia referem-se a esses saberes como a junção de três conhecimentos, classificados em linguístico, de mundo e compartilhado. Enquanto o conhecimento linguístico é utilizado apenas em parte na interpretação de um texto, “o estabelecimento do sentido de um texto depende em grande parte do conhecimento de mundo dos seus usuários, porque é só este conhecimento que vai permitir a realização de processos cruciais para a compreensão [...]" (Koch e Travaglia 2003: 60). O conhecimento de mundo é, segundo os autores, uma espécie de dicionário enciclopédico reunido na memória do indivíduo, que resgata informações do mundo e da cultura. 
Esses saberes que são ativados no momento de recepção dos enunciados vão ao encontro do contexto. Todo enunciado está necessariamente mergulhado em um contexto que, no momento da enunciação, inclina o enunciador na concretização de suas ideias em discursos (Koch \& Travaglia 2003: 27). Valer-nos-emos desses conhecimentos, aliados aos textos verbais e não-verbais, para compormos o contexto no qual as representações jornalísticas estão inseridas, privilegiando os aspectos de mercado.

\subsection{Cena da enunciação}

Seguindo os estudos de Maingueneau, temos que "um texto não é um conjunto de signos inertes, mas o rastro deixado por um discurso em que a fala é encenada" (Maiguneneau 2005: 85). A cena de enunciação é enquadrada pelo gênero do discurso e pelo espaço da enunciação instaurado pelo próprio discurso. No momento em que o enunciador cria o discurso, ele constrói um pano de fundo, uma diretriz que dita, inclusive, o desenvolvimento das ações do discurso. Devido à cena, que tem sua raiz no gênero de discurso, o enunciador sabe que deve consultar fontes, quais pessoas devem ser entrevistadas, quais informações devem ser priorizadas.

A partir dessas estruturas, cria-se a segunda dimensão da cena de enunciação, que compõe a representação. Maingueneau esclarece que a metáfora teatral é frequente entre os analistas de discurso inspirados pela corrente pragmática. Segundo a perspectiva pragmática, "a linguagem é considerada como uma forma de ação" (Maingueneau 1997: 29). Ou seja, um ato de fala implica uma ação e pressupõe um contrato de fala, no qual, de um lado, temos aquela que institui a ação e, de outro, aquele que realiza a ação. Conforme a analogia com o teatro, na arte da representação, "a cena de fala não pode, portanto, ser concebida como um simples quadro, uma decoração, como se o discurso sobrevivesse no interior de um espaço já construído e independente desse discurso. Ela é constitutiva dele" (Charadeau \& Maingueneau 2004: 95).

Isto é, a cena indica limites para a construção do discurso, visto que, antes de serem compostos, já se sabe em qual gênero de discurso os enunciados serão enquadrados. Simultaneamente, a cena é construída à medida que a enunciação se desenvolve. 
Existem três subdivisões para a cena da enunciação (Maingueneau 2004: 86). A cena englobante refere-se àquela que envolve o leitor em um determinado tipo de discurso. No caso de Veja, a cena englobante é a jornalística (tipo do discurso), mas isso não basta já que nem todos os leitores de Veja são jornalistas. É preciso ver como o discurso jornalístico os trata. Leitor crítico, leitor religioso, leitor conservador, leitor jovem, etc.

A cena genérica refere-se ao gênero do discurso e como o leitor é enquadrado em termos mais específicos. Trata, portanto, do papel que o leitor desenvolve no momento em que absorve o enunciado. Apesar das diferenciações elaboradas por Maingueneau, existe, entre cena englobante e genérica uma forte aproximação conceitual. Por isso, vamos preferir, em nossos estudos, o termo cunhado pelo próprio autor que traduz a união dessas duas cenas que resulta no quadro cênico. "É ele que define o espaço estável no interior do qual o enunciado adquire sentido - o espaço do tipo e do gênero de discurso" (Maingueneau 2004: 87).

$\mathrm{E}$, finalmente, tratamos da cenografia, última subdivisão de cena, definida como uma cena construída pelo texto especificamente. Um cenário montado, a dimensão de cena em que o enunciador tem mais liberdade para se mover dentro do tipo e do gênero de discurso.

\subsection{Ethos}

Em linhas gerais, o ethos consiste na "voz" do discurso, aquele que fala ao enunciatário. Para entendermos melhor esse conceito, retornamos à sua origem, na retórica, em que ethé era "as propriedades que os oradores se conferiam implicitamente, através de sua maneira de dizer: não o que diziam a propósito deles mesmos, mas o que revelavam pelo próprio modo de se expressarem" (Maingueneau 1997: 45, grifo do autor). É devido a esse traço do ethos que o enunciador passa a ser um fiador, aquele em quem se confia (Maingueneau 2004: 95-6).

O ethos persuade, mas não deixa essa intenção transparecer ao seu público.

O ethos funciona, assim, como uma auto-qualificação implícita, em que se reconhece o enunciador não pelo que ele diz de si mesmo, mas pela forma como diz, e esse percurso já se inicia pela escolha dos assuntos por ele abordados. Para uma aplicação mais adequada de ethos na $\mathrm{AD}$, é preciso notar que "esses efeitos são 
impostos não pelo sujeito, mas pela formação discursiva" (45). $\mathrm{Na} \mathrm{AD}$, a dimensão corpórea - gestos, tons de fala, etc., típicas dos discursos orais - é dispensada já que sua aplicação se dá também em textos escritos.

Mas os sentidos do enunciado permitem uma construção de sentidos acerca de duas dimensões do ethos (Maingueneau 1997: 98-99). O caráter está associado às características psicológicas da personagem do enunciador. Já o conjunto de determinações físicas e também a mobilidade do enunciador no espaço social são atribuídas à corporalidade. E todos esses traços do ethos do enunciador são apreendidos por meio das marcas textuais.

\subsection{Nome de marcas e produtos}

Esta categoria se engloba em um tipo de nome próprio específico, isto é, “o nome de marcas e seus correlatos, os nomes de produtos. Com essas marcas, nosso mundo se povoa de entidades que não são seres humanos, nem animais, nem objetos" (Maingueneau 2004: 207). Em seus estudos, o autor exemplifica essa categoria com os textos publicitários, mas nosso corpus, mesmo sendo um conjunto de matérias jornalísticas, incorpora essas marcas.

Existem três denominações para essa categoria. O nome da marca é um nome próprio que "refere-se a um agente coletivo, uma empresa, que possui simultaneamente propriedades ligadas a um indivíduo humano" (Maingueneau 2004: 208). O autor explica que a este nome são atribuídos os valores específicos como seriedade, juventude, etc.

Em publicidade, esses valores são necessários para criarem um diferencial em torno da marca, uma aura própria que irá valorizar a mercadoria em relação às demais.

Já o nome da categoria tem relação com o ramo produtivo de determinado produto. É um nome comum. Por fim, temos o nome do produto - que também é um nome próprio, pois designa "não um indivíduo único, mas um número a priori ilimitado de mercadorias idênticas" (Maingueneau 2004: 208). Assim, um nome de uma marca abarca diversos nomes de produtos, que, em geral, estão inseridos dentro de um mesmo nome de categoria.

\subsection{Análise de imagens}


Este item, além de decompor as fotografias, também incluirá análise de infográficos - que são híbridos entre as linguagens verbal e não-verbal - e dos boxes, em que alguns aspectos verbais são postos em destaque pelo arranjo visual das páginas.

Partiremos da concepção de que os sentidos do não-verbal e do verbal estão em constante relação, não podendo ser vistos de modo indissociável, mesmo porque, quando a reportagem se apresenta ao leitor, os elementos são simultâneos e confluentes. Para Joly, "é sua relação, sua interação, que produz o sentido que aprendemos a decifrar mais ou menos conscientemente e que uma observação mais sistemática vai ajudar a compreender melhor" (Joly 2005: 38).

Levaremos em conta, ainda, que as fotos analisadas são publicitárias, por reunirem características como pose, arranjo da cena e utilização de modelos. Assim, da imagem fotográfica pretendemos verificar o porquê de sua inserção na matéria e qual a sua relação com o verbal, em um exercício que requer um olhar insistente que mude, ao final, a impressão primeira de cada imagem.

\section{ANÁLISE DA REPORTAGEM}




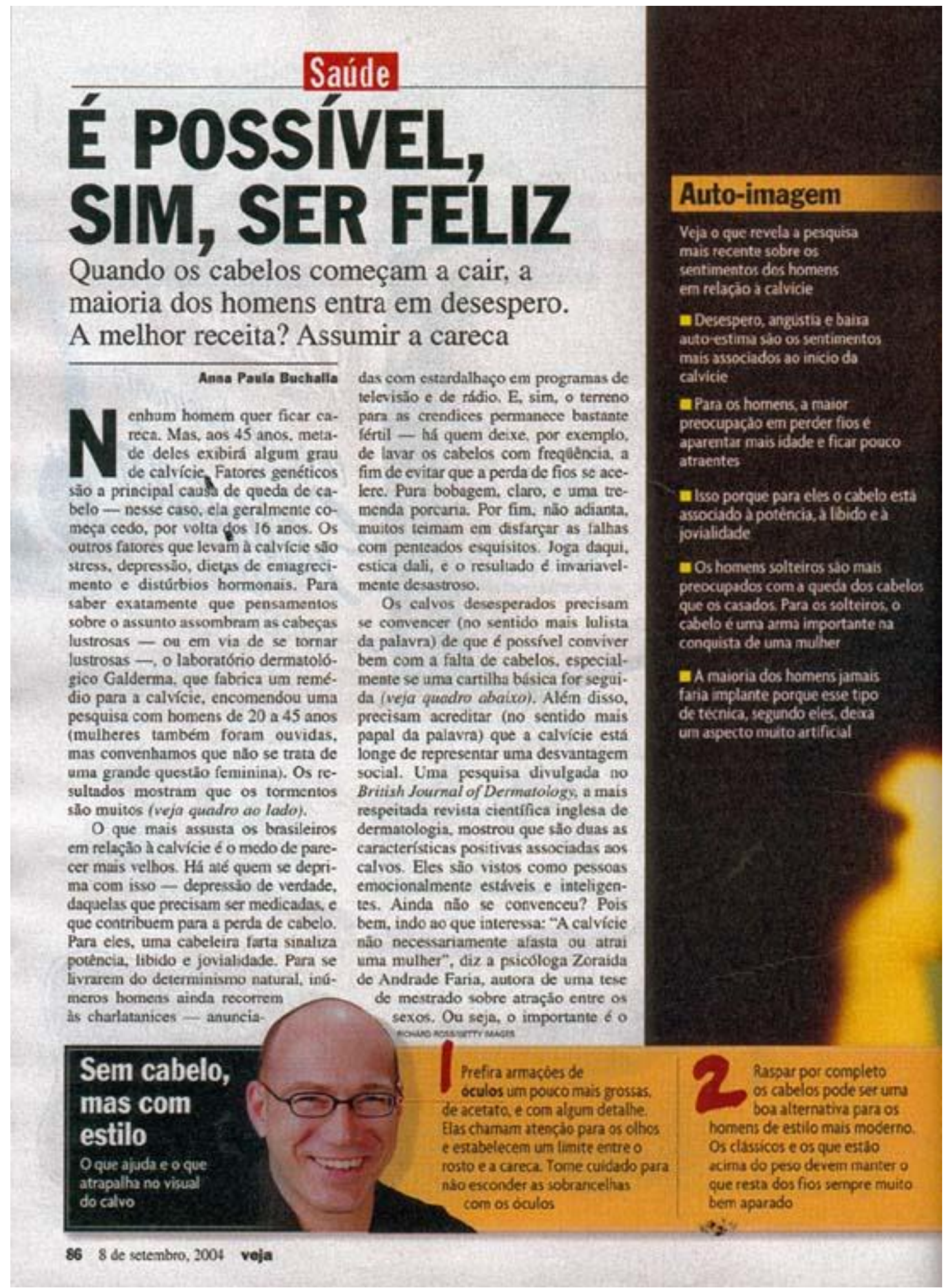

Fig. 1 - Matéria É possível, sim, ser feliz

Revista Veja, 8 de setembro de 2004, p.87 


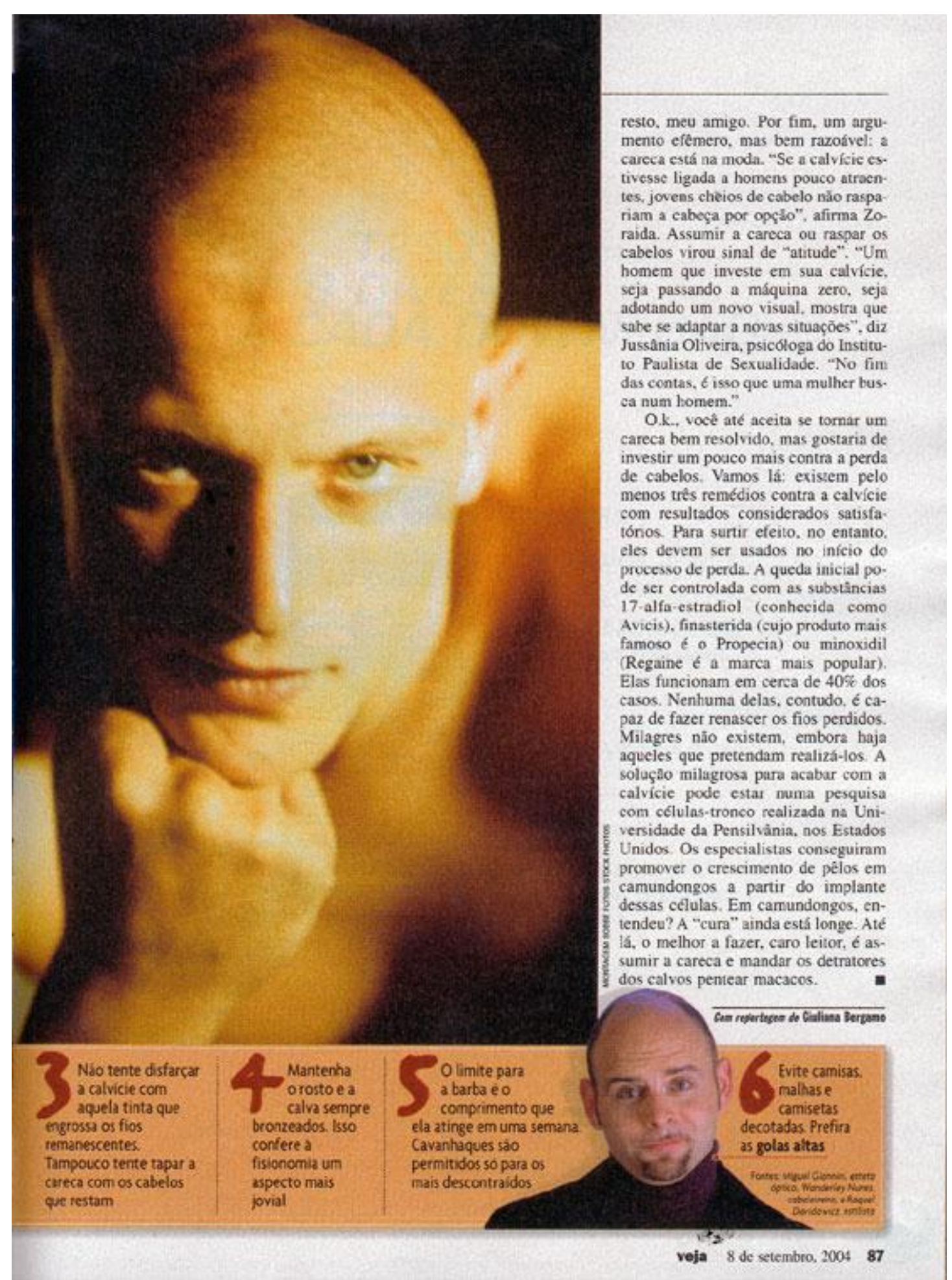

Fig. 2 - Matéria É possível, sim, ser feliz

Revista Veja, 8 de setembro de 2004, p. 88

Aparentemente, a matéria de saúde não traz nenhuma alusão a remédios, tratamentos, produtos, etc.: "Quando os cabelos começam a cair, a maioria dos homens entra em desespero. A melhor receita? Assumir a careca." (86) Mas logo após a abertura e o lide, surge provavelmente a razão da pauta do assunto. “[...] o laboratório 
dermatológico Galderma, que fabrica um remédio para a calvície, encomendou uma pesquisa com homens de 20 a 45 anos [...]” (86). Mais uma vez, a relação saúde está intrinsecamente ligada à estética já que a calvície não acarreta problemas no organismo, a não ser o desconforto causado pelos valores culturais que depreciam esteticamente os homens com essa característica.

Outra pesquisa, dessa vez divulgada pela revista científica de dermatologia British Journal of Dermatology, traz dois pontos positivos em relação à calvície, mas de maneira breve. A revista continua consultando fontes relacionadas ao assunto, no intuito de mostrar os benefícios de ser calvo - sendo que esta é a proposta da reportagem. Em um primeiro plano, o discurso parece aceitar a calvície, mas acaba induzindo a compra de medicamentos.

Todavia, no último parágrafo traz "três remédios contra a calvície são considerados satisfatórios". Ou seja, se a reportagem objetivava mostrar e provar que a calvície já está sendo aceita na sociedade, a especificação de medicamentos contra a calvície vai na contramão, porque ultrapassa um ponto de vista contrário. Ocorre, portanto, um apagamento por meio de uma oposição: “O.k., você até aceita se tornar um careca bem resolvido, mas gostaria de investir um pouco mais contra a perda de cabelos" (87, grifo nosso).

Assim, a revista põe a indicação de remédios para que o leitor possivelmente interessado possa perguntar ao seu médico. Ainda vale sublinhar que o produto Avicis é fabricado pela Galderma, indústria de medicamentos dermatológicos citada no início da reportagem.

\subsection{Contexto}

Na matéria, é possível perceber que a indústria farmacêutica tenta explorar um filão do mercado: os homens calvos. "Para saber exatamente que pensamentos sobre o assunto assombram as cabeças lustrosas [...] o laboratório dermatológico [...] encomendou uma pesquisa com homens de 20 a 45 homens [..]" (87)

Apesar de o problema da calvície ser encarado como um assunto de saúde, o enfoque de toda a reportagem é a estética, mesmo porque a calvície não afeta as funções essenciais do corpo e não atrapalha o desenvolvimento de ações básicas ao homem.

Culturalmente, a reportagem enfatiza o desfavorecimento dos homens calvos, mesmo que, aparentemente, venha com a proposta de contradizer a opinião já 
estabelecida. A abertura da matéria reforça ainda mais o repúdio à calvície: "Nenhum homem quer ficar careca". Em "Para se livrarem do determinismo natural" (grifo nosso), o verbo indica que se trata de algo negativo.

O contexto trabalha com a alteridade, como um jogo de espelhos; fala de como o homem é visto pelas mulheres e como ele se vê pela sociedade. O problema da calvície não é visto pela ótica da saúde, como preconiza o chapéu da matéria - que a inclui na editoria de saúde. A calvície é vista exclusivamente pelo viés da beleza já que, em termos práticos, não traz malefícios à saúde do homem (como dissemos anteriormente).

\subsection{Cena da enunciação}

O quadro cênico relaciona-se ao contexto à medida que a reportagem, trazendo à tona todo o preconceito existente em relação à calvície, também trata o leitor de duas formas: reforçando o preconceito dos outros em relação ao careca ou reforçando uma auto-rejeição. Importante destacar que, gradativamente, o texto busca atingir o leitor que se incomoda com a calvície. Em "Os calvos desesperados precisam se convencer [...]”, ele se refere aos calvos como uma pessoa à parte de sua conversa com o leitor. Depois, no mesmo parágrafo, já ocorre a transição e o texto mostra que seu leitor é o próprio calvo desesperado: "Ainda não se convenceu?". No trecho que inicia o último parágrafo, temos a evidência de que a matéria é produzida para um leitor (definido) que tem calvície. "O.k., você até aceita se tornar um careca bem resolvido, mas gostaria de investir um pouco mais contra a perda de cabelos".

Esses fragmentos também implicam uma transferência da cena englobante (que integra o quadro cênico), ao imprimir na matéria jornalística o reforço da função fática, típica do texto publicitário, em que a linguagem é trabalhada a fim de persuadir a outra extremidade de quem o produz.

O texto não traz marcas que estabelecem claramente uma cenografia, mas o terreno da conquista amorosa é evocado pelo texto, abrindo ainda mais as possibilidades do desenvolvimento da representação discursiva.

\subsection{Ethos}

O ethos assume, nesse texto, a função do conselheiro, que tem saberes suficientes para opinar sobre o assunto e pode, com segurança, dar dicas ao leitor, como 
no trecho "Ou seja, o importante é o resto, meu amigo" e "Até lá, o melhor a fazer, caro leitor, é assumir a careca e mandar os detratores dos calvos pentear macacos".

A voz que fala no texto é próxima ao leitor, a ponto de poder tratá-lo de maneira informal. Além de ser uma característica do veículo revista, essa também é uma forma de convencê-lo.

O ethos "leva" pessoas (médicos, pesquisadores) até esse leitor, que está preocupado com sua condição física. É um conselheiro que luta pela felicidade alheia e, para ajudar, apresenta todas as alternativas para ver o leitor mais feliz.

Mas, implicitamente, reforça cada vez mais o estereótipo que ronda a questão da calvície no Brasil, como por exemplo, ao referir-se aos calvos com a metonímia “cabeças lustrosas” que confere também um tom jocoso e pejorativo.

Esse mesmo ethos assume uma postura sincera, daquele que não quer que seu leitor acredite em crendices. E, para isso, desqualifica qualquer tentativa que não seja a do auto-convencimento (bloqueada pelo tom irônico com que se refere aos calvos) e dos remédios (que aparecem como uma solução real para o problema): "Para se livrarem do determinismo natural, inúmeros homens ainda recorrem às charlatanices [...]. E, sim, o terreno para as crendices permanece bastante fértil [...]. Pura bobagem, claro, e uma tremenda porcaria". Lança-se mão, portanto, de adjetivações e emprego de substantivos utilizados na linguagem coloquial. Tudo para aproximar o ethos de seu leitor. O ethos dá sua opinião, assume uma postura frente a esses recursos e desqualifica quem os utiliza: "Joga daqui, estica dali, e o resultado é invariavelmente desastroso".

\subsection{Nome de marcas e produtos}

A categoria que figura na reportagem é a dos remédios. O nome do laboratório dermatológico Galderma é o único que aparece como nome de marcas. Nesta matéria, os nomes dos produtos são elencados pela revista: Avicis, Propecia e Regaine. Percebemos que a reportagem não privilegia nenhum deles. Apesar de não haver citação do nome das marcas, as três indústrias que produzem são multinacionais, duas delas norte-americanas: O Avicis é produzido pela Galderma (franco-suiça); o Propecia é fabricado pela Merck Sharp \& Dohme - MDC; enquanto o Regaine é fabricado pela indústria Pharmacia \& Upjohn Co. 
Além de confirmar as palavras de Marília Scalzo (2003), que vê a revista como um grande catálogo de produtos, essa lista mostra o enfraquecimento do Brasil na produção de medicamentos e evidencia o fortalecimento das multinacionais nesse ramo, que se volta cada vez mais à exploração de um mercado direcionado à estética. E a imprensa, representada em nossa análise por Veja, acaba divulgando essas ideias de que a satisfação com o corpo pode ser alcançada, mesmo que parcialmente, com o uso de remédios.

De modo geral, a reportagem dissemina, na representação formada, a idéia de que os remédios são eficazes. "Elas [substâncias] funcionam em cerca de $40 \%$ dos casos". Esse discurso opera na superestrutura ao abordar os remédios como a solução mais viável (haja vista que nenhuma marca textual desqualifica o poder dessas substâncias).

A matéria jornalística passa a ter elementos publicitários à medida que encara 0 leitor como consumidor e divulga de forma ampla uma série de produtos que não são tão acessíveis ao grande o público, mas sim ao público leitor de Veja. A reportagem, a exemplo da publicidade, integra as estratégias de marketing.

\subsection{Fotografias}

O modelo da primeira fotografia é muito semelhante ao nadador brasileiro Fernando Scherer, mas a revista não traz nenhuma marca que possa comprovar esse dado. O modelo traz características aceitas culturalmente que lhe conferem beleza: olhos claros, pele clara, além de ser jovem.

Em close, ele olha para a câmara como se encarasse de frente o leitor e assumisse sua calvície. A iluminação reflete um lado do rosto, e destaca também sua falta de cabelo. A calvície, na foto, compete com a beleza do modelo.

A imagem relaciona-se ao texto ao seu lado, intitulado "Auto-imagem”, que traz as maiores preocupações dos homens calvos. A expressão séria do modelo entra em consonância com o texto, que destaca da matéria os resultados da pesquisa encomendada pela Galderma.

Ambas as fotos que complementam o box trazem homens carecas e felizes. Eles representam o que o texto verbal fala de "estilo": usam óculos com aros grossos e blusas de golas altas (conforme as dicas 1 e 6) para que os calvos não cometam deslizes ao 
comporem o seu visual e incorporem detalhes que desviem a atenção da careca para um detalhe do vestuário.

\subsection{Box}

Completando o que foi dito anteriormente, todas as dicas são voltadas para que se disfarce o problema da saúde, entrando em contradição com a premissa do texto de que "assumir a careca" é o melhor a fazer. "Eles [óculos] chamam a atenção para os olhos e estabelecem um limite entre o rosto e a careca". A dica $\mathrm{n}^{\circ} 4$ "mantenha o rosto e a calva sempre bronzeados. Isso confere à fisionomia aspecto mais jovial" reforça ainda mais o medo dos homens de que os carecas parecem mais velhos. As dicas, portanto, reiteram que ser calvo não é socialmente aceito e operam o processo ideológico de viabilizar significados que atribuem valores determinados e estabelecidos. Esses valores vão preparar o leitor para ampliar sua receptividade à alternativa dos remédios.

O problema sempre tenta ser solucionado no plano da aparência, e não do convencimento e da tentativa de mudança da cultura de que ser calvo é um traço comum a muitos homens e que, por isso, deve tornar-se, também, normal, assim como as rugas para pessoas de idade.

\section{CONSIDERAÇÕES FINAIS}

A análise empreendida nos indica que há uma intersecção entre as linguagens jornalística e publicitária na reportagem sobre saúde em Veja. A proposta é jornalística, mas a finalidade é publicitária. Com o objetivo de vender, ou criar um hábito do consumo de remédios em seu público, a revista utiliza, como meio, a informação (seja ela, em muitos casos, parcial e incompleta). Os recursos de linguagem são de ambos jornalismo e publicidade. A aproximação é estreita.

Ao ressaltar as vantagens dos remédios e promover o apagamento dos possíveis efeitos colaterais e riscos oferecidos pelos tratamentos, o jornalismo de Veja aproximase da publicidade (da informação voltada ao consumo). Afinal, a partir desse tipo de reportagem, a revista cria um ambiente propício aos anunciantes. Existe uma sincronia entre o factual (jornalístico) e o fictício (publicidade). 
A fotografia principal indica que os padrões que vigoram não são os do indivíduo comum, mas do indivíduo reconhecido pela beleza em um amplo espaço social. Ressaltemos, ainda, que a dimensão fotográfica se apoia muito mais no valor estético do que no valor informativo. A busca se dá para estar em consonância com o que o mundo estabeleceu como felicidade.

Essa constatação nos leva a uma visão crítica do fazer jornalístico que, ao mesmo tempo em que tenta suprir os anseios dos leitores - consumidores potenciais -, acaba reduzindo a saúde à área estética. Simultaneamente, corrobora para a rigidez dos valores culturais, que exigem cada vez mais que os indivíduos alcancem, num suplício interminável, metas instáveis como a felicidade e o sucesso.

Não podemos sacrificar o jornalismo e condená-lo à subordinação da publicidade. Uma prática menos mercadológica, que privilegie informações relevantes e responsáveis, ainda que comprometa a imagem de determinado fármaco, deve ser adotada por qualquer veículo que se classifica como jornalístico.

\section{REFERÊNCIAS BIBLIOGRÁFICAS}

BARTHES, R. O óbvio e o obtuso. Rio de Janeiro, Nova Fronteira, 1990.

CHARADEAU, P; MAINGUENEAU, D. Dicionário de análise do discurso. São Paulo, Contexto, 2004.

DAHLET, P. "Leitura e construção do sentido: a perspectiva enunciativa" in: MEC (org.) A formação do leitor: o papel das instituições de formação do professor para a educação fundamental, vol.4, Brasília, 1994, p. 90 a 103.

JOLY, M. Introdução à análise da imagem. São Paulo, Papirus, 2005.

KOCH, I. G. V.; TRAVAGLIA, L. C. Texto e coerência. São Paulo, Cortez, 2003.

MAINGUENEAU, D. Novas tendências em análise do discurso. Campinas, São Paulo, Pontes / Ed. da Unicamp, 1997.

MAINGUENEAU, D. Análise de textos de comunicação. São Paulo, Cortez, 2004.

SCALZO, M. Jornalismo de revista. São Paulo, Contexto, 2003.

Artigo recebido: 23/03/2010

Artigo aprovado: 27/05/2010 